\title{
Molecular approach to find target(s) for oligoclonal bands in multiple sclerosis
}

\author{
Kenneth H Rand, Herbert Houck, Nancy D Denslow, Kenneth M Heilman
}

\begin{abstract}
Objectives-Oligoclonal bands are a characteristic finding in the CSF of patients with multiple sclerosis, yet their target antigen(s) remain unknown. The objective was to determine whether a filamentous phage peptide library could be employed to allow the oligoclonal bands to select their own target epitopes.
\end{abstract}

Methods-CSF IgG antibody from 14 patients with multiple sclerosis and 14 controls was used to select individual phage clones from a bacteriophage library containing $\approx 4 \times 10^{7}$ different hexamers expressed on its surface pIII protein. The amino acid sequence selected was deduced by sequencing the DNA of the genetically engineered insert.

Results-In general, after three rounds of selection, CSF from both patients with multiple sclerosis and controls selected one to two consistent peptide motifs. Five out of 14 patients with multiple sclerosis, and one control, selected the amino acid sequence motif, RRPFF. Given 20 possible amino acids per position, the likelihood of five patients selecting the same linear five amino acid sequence is at most $1.6 \times 10^{-13}$, corrected for the number of clones sequenced. A GenBank computer search showed that this sequence is found in the Epstein-Barr Virus nuclear antigen (EBNA-1), and a heat shock protein $\alpha B$ crystallin. Human serum antibodies to a synthetic peptide containing RRPFF were virtually exclusively found in patients with prior infection by Epstein-Barr virus. Other studies have suggested a relation between Epstein-Barr virus infection and multiple sclerosis, including nearly $100 \%$ Epstein-Barr virus seropositivity among patients with multiple sclerosis and increased concentrations of antibody to EBNA in CSF of patients with multiple sclerosis. By antigen specific immunoblotting, antibodies to the RRPFF motif in the CSF were shown to correspond to a subset of oligoclonal bands in the CSF from the same patient.

Conclusion-This study shows that phage epitope display libraries may be used to select amino acid motifs which are potentially relevant to the pathogenesis of multiple sclerosis.

(f Neurol Neurosurg Psychiatry 1998;65:48-55)

Received 9 September 1997 and in revised form 9

December 1997

Accepted

9 December 1997
Keywords: oligoclonal bands; multiple sclerosis; filamentous phage display library; EBNA-1
Introduction

OLIGOCLONAL BANDS

Cerebrospinal fluid from patients with multiple sclerosis contains monoclonal antibodies that can be identified as oligoclonal bands by isoelectric focusing (IEF). These oligoclonal bands are one of the most consistent laboratory abnormalities found, being detectable in about $95 \%$ of patients with clinically definite multiple sclerosis compared with roughly $10 \%-15 \%$ of controls. $^{1-5}$ Oligoclonal bands are routinely found in encephalitis and meningitis caused by infectious agents such as enterovirus, herpes simplex type 1, human immunodeficiency virus, measles (as found in subacute sclerosing panencephalitis), and even bacterial infections such as Lyme borreliosis, neurosyphilis, and tuberculous meningitis. ${ }^{6-10}$ Although the oligoclonal bands in these infectious diseases can be shown to be directed towards the infecting agent, the identification of a target infectious agent or autoantigen for the oligoclonal bands in multiple sclerosis has not been accomplished.

Several studies have attempted to identify the target of the oligoclonal bands. In patients with multiple sclerosis, antibodies to myelin basic protein in CSF, serum, and brain eluates are found with variable frequency. Using agarose isoelectric focusing with transfer to nitrocellulose coated with or without myelin basic protein (antigen specific immunoblotting), Cruz et $a l^{11}$ found oligoclonal bands that reacted with myelin basic protein in nine of 28 (32\%) of patients with multiple sclerosis, compared with none of 34 control patients with other neurological diseases. However, these bands could be clearly separated on their immunoblots from those oligoclonal bands stained by silver or by antihuman IgG. ${ }^{11}$ Likewise oligoclonal bands reactive with measles virus did not comigrate with oligoclonal bands reactive with myelin basic protein, nor with the oligoclonal bands demonstrable by direct staining methods in their patients with multiple sclerosis. ${ }^{11}$ Other studies using imprint immunofixation for measles, mumps, rubella, HSV-1, varicella, cytomegalovirus, and adenovirus similarly showed antigen specific oligoclonal bands; however, these bands did not correspond to those seen by direct staining using Coomassie blue. ${ }^{12}$ Studies with various brain components, such as lipidproteolipid, ganglioside, myelin basic protein, and saline extracts of both normal and multiple sclerosis brain gave similar results. ${ }^{13}$ Souberbielle $e t a l^{14}$ did not find any significant number of serum samples from multiple sclerosis or control patients which reacted with human brain vessels by western blot. Thus, although patients have various intrathecally synthesised autoantibodies and antiviral antibodies in CSF, 
none have been identified directly with the oligoclonal bands found by staining methods. On the other hand, in animal models of experimental autoimmune encephalomyelitis (EAE), oligoclonal bands are found and can be shown to react with the antigen used to induce the encephalitis. ${ }^{15}$

PEPTIDE EPITOPE LIBRARIES

In recent years, methods have been developed which permit monoclonal antibodies to select their own target epitopes. Although synthetic libraries have been developed, ${ }^{16}$ expression of random amino acid inserts into either the pIII or pVIII protein of M13 bacteriophage has been achieved by several groups. ${ }^{17-23}$ Briefly, a short nucleotide sequence is synthesised in such a way as to code for a random amino acid at each of six or more positions. This DNA is then inserted into the bacteriophage gene coding for a surface protein, with the result that each phage in the population displays a unique amino acid sequence on its surface.

Scott and Smith ${ }^{17}$ have shown that monoclonal antibodies can indeed select phage from their library, the inserts of which express epitopes closely matching the known target of these antibodies. They used two monoclonal antibodies against myohaemerythrin, the target epitope of which was known to be the linear sequence DEFLKI and found that all 33 clones isolated after three rounds of selection contained DEFXXX as the first three amino acids of the hexapeptide, and 19 of 33 contained the first four, DEFLXX. Similar consistency was also achieved by Cwirla et $a l^{19}$ using a monoclonal antibody to $\beta$ endorphin, and by Koivunen et $a l^{4}$ for the RGD motif of the binding site of $\alpha_{5} \beta_{1}$ integrin for fibronectin. Likewise, Devlin demonstrated the selection of a consistent motif for the biotin binding site of streptavidin, ${ }^{18}$ and Lenstra et al obtained similar results with monoclonal antibodies to the spike protein of coronavirus. ${ }^{25}$ More recently, this methodology has been applied to the identification of a serotype specific epitope of Dengue virus $1 .{ }^{26}$

In this study, CSF immunoglobulin G (IgG) was allowed to select specific amino acid sequences from a filamentous bacteriophage display library as an initial approach toward the identification of the target epitopes of the oligoclonal bands in the CSF of patients with multiple sclerosis.

\section{Methods}

PATIENTS AND CONTROLS

Permission was obtained from the Institutional Review Board at both the University of Florida and the Gainesville Veteran's Affairs Medical Center to recruit volunteers with multiple sclerosis to undergo lumbar puncture. All volunteers underwent a complete history and neurological examination at the University of Florida Neurology clinic by one of the authors $(\mathrm{KMH})$. Volunteers willing to undergo lumbar puncture were recruited from the North Florida Chapter of the Multiple Sclerosis Society and by word of mouth. A total of nine potential subjects volunteered, but three were excluded (one because of concomitant autoimmune disease, one because of severe coronary artery disease, and one because of prior brain surgery). Two additional volunteers initially agreed to participate but one never followed through, and the other was told not to participate by her private physician. CSF was also obtained from the Chemistry Laboratory, Shands Hospital, Gainesville Fl, USA when oligoclonal bands were detected by agarose gel isoelectric focusing electrophoresis and Coomassie blue staining of $80 \times$ concentrated CSF. If CSF contained oligoclonal bands, the patient's chart was reviewed and those patients with a clinical diagnosis of multiple sclerosis were included for further study (see below). Control CSFs were also obtained from the clinical laboratory. Charts of these patients were reviewed to rule out possible multiple sclerosis but other neurological disease was not excluded.

All patients with multiple sclerosis had a clinical diagnosis of multiple sclerosis and were receiving treatment for it. Multiple sclerosis patients 1,3 , and 6 were selected because they had very intense oligoclonal bands on CSF electrophoresis and patients 2, 4, 5, and 11 were volunteers. Samples of CSF from patients 6-10 and 12-14 were obtained from the clinical laboratory but were not selected on any clinical or laboratory basis. All patients with multiple sclerosis except 1 and 6 met the criteria of Schumacher et al for a clinically definite case. ${ }^{27}$ All had oligoclonal bands when tested in the clinical laboratory, except patient 11 .

CSF from 14 patients undergoing lumbar puncture for the diagnosis of other neurological conditions was also obtained from the clinical laboratory. Control patients carried the following diagnoses or conditions: unexplained seizure one, probable Guillain-Barré syndrome one, cervical disc related paraesthesias one, neurosarcoid two, follow up of treatment for CNS leukaemia one, status postcerebrovascular accident two, rule out meningitis in a sepsis investigation one, CNS lymphoma one, staphylococcal endocarditis receiving vancomycin with mental status changes one, status postheart transplant with mild cerebral atrophy and recent herpes zoster one, status migranosis one, and intraventricular neurocytoma one. The two patients with neurosarcoid had cell counts of 13 and $16 \times 10^{6}$ white blood cells $/ 1$, and one of them had a protein of $3880 \mathrm{mg} / \mathrm{l}$ and a slightly low glucose of $2.1 \mathrm{mmol} / 1$. Otherwise all CSF cell counts, glucose, and protein results were normal.

\section{PHAGE LIBRARY}

The phage expression library was a $50 \mu$ l aliquot amplified from the $2 \times 10^{8}$ clone library described by Scott and Smith ${ }^{17}$ and was generously provided by Dr George Smith, University of Missouri. This library has a titre of $9.4 \times 10^{12}$ $\mathrm{TU} / \mathrm{ml}$ and a physical particle concentration of $2.7 \times 10^{14}$ virions $/ \mathrm{ml}$. Sequencing en masse showed the expected degeneracy of the 18 base pair insert, with no visible evidence of bias at any position. ${ }^{17}$ The library was propagated in K91 Kan $E$ coli, which was also a gift from Dr George Smith. 
Table 1 Consistency of motif selection by CSF on repeat testing

\begin{tabular}{lll}
\hline $\begin{array}{l}\text { MS patient } 4 \\
\text { Experiment } 1\end{array}$ & Experiment 2 & Experiment 3 \\
\hline RRPFFH & & RRPFFR \\
RRPFFR & & \\
RRPFFR & & \\
RRPFFR & & \\
RRPFFM & & \\
RRPFFM & & PLTRTA \\
RRPFFL & & \\
RRPFFI & & \\
PLVRVA & & \\
PLVRVA & & \\
PLVRVA & & \\
PLVRVA & & PPHFPP \\
ELVRVA & ELVRVA & PPHFPP \\
ELVSVA & ELIRTA & \\
LLVRVA & & \\
PPHAPP & PPHAPP & \\
PPHAPP & PPHAPP & \\
& PPHAPP & \\
& PPHAPP & \\
& PPHAPP & \\
DGWRGL & PPHAPP & \\
RASLAI & PPHAPP & \\
AWDLIF & PPHPPI & \\
\hline
\end{tabular}

SELECTION OF EPITOPES FROM PEPTIDE LIBRARY Streptavidin coated magnetic beads (Dynabeads, Dynal Inc, Lake Success, NY, USA) were washed once in $50 \mathrm{mM}$ Tris $\mathrm{pH} 7.5,150$ $\mathrm{mM} \mathrm{NaCl}$ and $0.05 \%$ Tween 20 (TBST). Approximately $100 \mu$ beads $\left(\approx 6-7 \times 10^{7}\right.$ beads) were incubated for two to four hours on a rotating tube holder at $4^{\circ} \mathrm{C}$ with $10 \mu \mathrm{g}$ biotin labelled mouse monoclonal antihuman IgG (Zymed Labs Inc, San Francisco, CA USA cat No 05-4240) in a volume of $200 \mu \mathrm{l}$ TBST. After washing $\times$ three with TBST, $0.1 \mathrm{ml}$ beads were incubated with $10 \mu \mathrm{l} \mathrm{CSF}$ diluted to $200 \mu \mathrm{l}$ with TBST overnight at $4^{\circ} \mathrm{C}$ with mixing. Unblocked streptavidin binding sites were blocked with $1 \mathrm{mM}$ biotin included in the TBST used for all steps from this point on. After five washes with TBST using the magnetic separator, the beads with bound CSF were incubated with 10 $\mu \mathrm{l}$ phage library in a final volume of $200 \mu \mathrm{l}$ overnight at $4^{\circ} \mathrm{C}$. After 10 washes in TBST, the bound phage were eluted from the beads by incubation in $100 \mu 100 \mathrm{mM} \mathrm{HCl}, \mathrm{pH} 2.2$ for five minutes, followed by a rinse with a second volume of $100 \mu \mathrm{l} \mathrm{HCl}$ at $\mathrm{pH} 2.2$. The two $\mathrm{HCl}$ volumes were combined and immediately neutralised in $38 \mu \mathrm{l} 1 \mathrm{M}$ Tris, $\mathrm{pH}$ 9.1. Phage were then used to infect K91 Kan E coli in LB broth overnight, harvested the next day by polyethylene glycol (PEG) precipitation, washed, and the process repeated twice more. After the third elution, phage infected K91 Kan $E$ coli were plated and the colonies at the end point of the titration grown for sequencing. After extraction of the DNA, the insert was sequenced by standard methods and the amino acid sequence of the insert deduced from the DNA sequence. Except for the use of the streptavidin magnetic beads, this procedure is essentially identical to that of Scott and Smith. ${ }^{17}$

\section{SEQUENCING}

Phage clones were grown in $E$ coli and prepared for sequencing by PEG precipitation, phenol chloroform extraction, and ethanol precipita- tion as described. ${ }^{17}$ Sequencing was carried out with a Sequenase ${ }^{\mathrm{TM}}$ version 2.0 sequencing kit (US Biochemical, Cleveland, OH, USA) according to the instructions provided by the manufacturer.

For multiple sclerosis patients $1-5,7$, and 8 and control patients 1-3, 20 clones/patient were sequenced. For the remaining patients only 10 clones/patient were sequenced. In some patients whose CSF was repeatedly tested, only five clones were sequenced (table 1).

ISOELECTRIC FOCUSING, BLOTTING, AND IMMUNOPEROXIDASE ASSAY

Undiluted CSF and serum samples diluted to roughly the same IgG concentration were applied to precast $\mathrm{RESOLVE}^{(\mathrm{R})}(\mathrm{pH} 3-10,85$ $\mathrm{mm} \times 100 \mathrm{~mm} \times 1 \mathrm{~mm}$ thick) agarose isoelectric focusing gels (IsoLab Inc, Akron, OH, USA). Anode wicks were soaked in $0.5 \mathrm{M}$ acetic acid and cathode wicks in $0.5 \mathrm{M} \mathrm{NaOH}$. The gel was focused in a Hoefer Isobox isoelectric focusing flatbed unit (Hoefer Scientific Instruments, San Francisco, CA, USA) at $5^{\circ} \mathrm{C}$ and $5 \mathrm{~W}$ for 15 minutes, $10 \mathrm{~W}$ for 15 minutes, and $15 \mathrm{~W}$ until complete as determined by migration and resolution of methyl red dye loaded 1 $\mathrm{cm}$ from the cathode wick. Voltage was limited to $1500 \mathrm{~V}$. Isoelectric point markers ranging in pI from 3.6-9.3 (Sigma, St Louis, MO,USA) were run in the outer lanes.

Immediately after the run, pI marker lanes were cut from the gel and stained with $0.1 \%$ Coomassie brilliant blue R-250 in $25 \%$ ethanol, $9 \%$ acetic acid. Serum and CSF lanes were preblotted with dry nitrocellulose (NC) paper (either $0.45 \mu$ Biorad, Hercules, CA., USA, or $0.45 \mu$ Schleicher and Schuell, Keene, NH, USA) for 15 seconds to remove cross reacting high molecular weight aggregates and cell fragments that can result in smeared blots. ${ }^{28}$ Proteins were then blotted on to either uncoated NC paper, hydrated in Tris buffer, $\mathrm{pH} 7.4$ or NC paper coated with a $300 \mu \mathrm{g} / \mathrm{ml}$ solution of goat antihuman IgG Fc (Sigma, St Louis, MO, USA), for determination of total IgG or NC paper coated with $800 \mu \mathrm{g} / \mathrm{ml}$ avidin and 300 $\mu \mathrm{g} / \mathrm{ml}$ biotinylated peptide for detection of peptide specific IgG. Transfer of proteins was performed for 30 minutes as follows: NC paper was carefully placed over the gel, air bubbles were removed, and the NC paper was overlaid with one piece of Tris buffer soaked QuickDraw $^{(\mathrm{TM})}$ extra thick blotting paper (Sigma) followed by several layers of paper towels. A glass plate was placed on top of the assembly and weighted down with a $1 \mathrm{~kg}$ weight.

If not assayed immediately, blots were air dried. They were rinsed briefly in phosphate buffered saline (PBS), $\mathrm{pH} 7.4$, rinsed once with PBS plus $0.05 \%$ Tween-20 (PBST), then incubated with a blocking solution of $1 \%$ BSA in PBST plus $0.05 \%$ sodium azide for one hour. Bound IgG was detected by incubating blots with a 1:500 dilution of goat antihuman IgG peroxidase (Sigma) for one hour. After rinsing with three $50 \mathrm{ml}$ volumes of PBST, the substrate 3,3'-diaminobenzidine tetrahydrochloride (Sigma) at $180 \mu \mathrm{g} / \mathrm{ml}$ plus $0.01 \%$ $\mathrm{H}_{2} \mathrm{O}_{2}$, was added until a brown precipitate was 
seen. The reaction was stopped with excess water and the blots dried before analysis.

PREPARATION OF QUANTITATIVE ISOELECTRIC

FOCUSING FRACTIONS

For quantitative preparation of isoelectric focusing fractions $1 \mathrm{ml} \mathrm{CSF}$ was concentrated to $\approx 70$ $\mu \mathrm{l}$ and applied across the entire gel in a wide band. After focusing, the gel was cut in two vertical strips one $\approx 0.5 \mathrm{~cm}$ wide for staining the $\mathrm{pI}$ markers and oligoclonal bands and the remaining portion for "snow plowing". The gel was lined up on graph paper and narrow strips of about $2.5 \mathrm{~mm}$ in width were scraped from the plastic backing ("snow plowed") with a thin spatula and placed in microfuge tubes. IgG was extracted from the gel by repeated freeze thawing in the presence of $0.5-1.0 \mathrm{ml} 20 \mathrm{mM}$ Tris, $0.3 \mathrm{mM} \mathrm{NaCl}$, pH 7.4 with $0.02 \% \mathrm{NaN}_{3}$. This procedure produced fractions containing an estimated zero to two visualisable oligoclonal bands. Each fraction was washed and centrifuged $\times$ three in an $0.22 \mu$ Spin X centrifuge tube (Costar, Cambridge, MD, USA) and the collected supernatant concentrated $\times$ two in a Microcon 10 microcentrifuge tube (Amicon, Beverley, MD, USA) to a final volume of $\approx 100 \mu \mathrm{l}$, which was used for three rounds of selection with the phage library as described above.

PEPTIDE SYNTHESIS

Peptides were prepared by solid phase methodology, using FMOC chemistry on an Applied Biosystems 322A peptide synthesiser, in the Interdisciplinary Center for Biotechnology Protein Chemistry Core Facility at the University of Florida, Gainesville, Florida, USA.

ENZYME LINKED IMMUNOSORBENT ASSAY (ELISA) Nunc microwell module F-16 (Nunc Roskilde, Denmark) wells were coated with $100 \mu \mathrm{l}$ of a 20 $\mu \mathrm{g} / \mathrm{ml}$ solution of the appropriate peptide in

Table 2 Epitope selection by $p H$ fractions from isoelectric focusing

Patient 4

\begin{tabular}{ll} 
Fraction $11(\mathrm{pH} \approx 8.8)$ & Fraction $16(\mathrm{pH} \approx 8.0)$ \\
PPHPPI $\times 9$ & Clones lost \\
PASAMI & Fraction $17(\mathrm{pH} \approx 7.8)$ \\
Fraction $12(\mathrm{pH} \approx 8.6)$ & LWWWFS \\
PPHFPP $\times 3$ & PWWWFS \\
PPHLPP & PPFPPI \\
PPHPPP & PPFPPN \\
& LALSAS $\times 2$ \\
TAHPPP & RPMLVF \\
& AQFNVP \\
Fraction $13(\mathrm{pH} \approx 8.5)$ & \\
PFHPPP $\times 2$ & Fraction $18(\mathrm{pH} \approx 7.6)$ \\
PPTRVA & PFHPPP $\times 4$ \\
PPTRVA & PAFLPP $\times 4$ \\
PLTRVA & FRWPEH $\times 2$ \\
PLTRVR & \\
PLVNVA & Fraction $19(\mathrm{pH} \approx 7.5)$ \\
REWHSL $\times 2$ & PRFLPP $\times 4$ \\
Fraction $14(\mathrm{pH} \approx 8.3)$ & PPWLPL $\times 2$ \\
ELVSVA $\times 7$ & PPFAPR \\
ELVRVA $\times 3$ & PQHPPP \\
Fraction $15(\mathrm{pH} \approx 8.2)$ & PAHQMP \\
PLVRVA $\times 5$ & PHFSPP \\
PLIRVA & \\
PLINVA & Fraction $20(\mathrm{pH} \approx 7.3)$ \\
PLTCVA & PAFLPP $\times 5$ \\
ELIRVA & PFFLPP $\times 4$ \\
\hline
\end{tabular}

$100 \mathrm{mM}$ carbonate buffer, $\mathrm{pH} 9.6$ overnight at $4^{\circ} \mathrm{C}$. Wells were then rinsed once with phosphate buffered saline containing $0.05 \%$ Tween-20 (PBST) and blocked for two hours at $37^{\circ} \mathrm{C}$ with PBST with $5 \%$ fetal bovine serum (PBST-FBS). Serum was diluted 1:50 in PBST and CSF was diluted $1: 4$ in PBST-FBS and $100 \mu \mathrm{l}$ incubated for one hour at $37^{\circ} \mathrm{C}$. Wells were then rinsed three times with PBST and incubated with $100 \mu \mathrm{l}$ of a 1:500 dilution of mouse antihuman IgG-alkaline phosphatase (Fisher Scientific, Atlanta, GA, USA) in PBST for one hour at $37^{\circ} \mathrm{C}$. Wells were rinsed three times with PBST, followed by the addition of $100 \mu \mathrm{l} 1 \mathrm{mg} / \mathrm{ml} p$-nitrophenyl phosphate substrate (Sigma) in $100 \mathrm{mM}$ glycine buffer, $\mathrm{pH}$ 9.6 for 30 minutes at room temperature $\left(22^{\circ} \mathrm{C}\right)$. Reactions were stopped by the addition of $100 \mu 11.5 \mathrm{M} \mathrm{NaOH}$ and read at $405 \mathrm{~nm}$. Negative control wells were coated with antigen, but received no CSF or serum.

EPSTEIN-BARR VIRUS AND CYTOMEGALOVIRUS SEROLOGY

Epstein-Barr virus serology was measured by immunofluorescence to the viral capsid antigen (VCA) using an indirect immunofluorescent assay (Gull Laboratories, Salt Lake City, UT, USA). A titre $\geqslant 1: 10$ was considered positive. Cytomegalovirus serology was measured by ELISA (Bartels, Issaquah, WA, USA). A titre was considered positive if the optical density was greater than that of the average of three low positive controls, supplied by the manufacturer.

\section{Results}

CSF from both multiple sclerosis and control patients generally selected one to three dominant amino acid sequence motifs, with only minimal variation in one or two amino acids within the motif (tables 1 and 2). This pattern of consistent selection of a peptide motif is essentially identical to that described by Scott and Smith and others for monoclonal antibodies. ${ }^{17-19}$ By contrast, when the mouse monoclonal antihuman IgG that was used to bind the human CSF IgG to the magnetic beads was used to select phage, a total of 16 different peptide sequences were found, only two of which showed sequence consistency. None of the sequences selected by the mouse antihuman IgG had any similarity to those of the patients with multiple sclerosis or the control patients (data not shown)

Table 3 shows the amino acid motifs most often selected by multiple sclerosis and control patients. The linear motif RRPFFX (where $\mathrm{X}=\mathrm{H}, \mathrm{R}, \mathrm{M}, \mathrm{L}, \mathrm{N}$, or I) was found in five of 14 patients with multiple sclerosis and one of 14 controls ( $p=0.074$, Fisher's exact probability). As there are 20 different amino acids per position in the random hexamer, the chances that any two random linear hexamer sequences selected by different subjects will have the same $5 / 6$ linear sequence is $\left(1 / 20^{5}\right)(2)$ or $1 / 1.6 \times 10^{6}$. When corrected for the total number of independent clones sequenced, the probability of finding five patients with multiple sclerosis with this same linear $5 / 6$ sequence by chance alone is at most $\approx 1.6 \times 10^{-13}$ (calculation given in 
Table 3 Amino acid motifs most often selected by patients with multiple sclerosis and controls

\begin{tabular}{lll}
\hline Motif & $\begin{array}{l}\text { Patients with multiple } \\
\text { sclerosis }\end{array}$ & Controls \\
\hline RRPFFX & 5 & 1 \\
PWX†WLX & 4 & \\
LYAAFY & 1 & \\
PWAAFY & 2 & 1 \\
PWIAFH & & 1 \\
PWFAFH & 2 & 1 \\
GDFVFI & 2 & 1 \\
GDWVFI & & \\
GDFAFV & 2 & 1 \\
PXHXPP & 1 & 1 \\
VPWFHF & 1 & 1 \\
PWFAFH & & \\
PQWPYC & 15 & \\
PQCPYC & & \\
AVYRPP & 15 \\
\hline
\end{tabular}

${ }^{\star} \mathrm{X}=\mathrm{H}, \mathrm{R}, \mathrm{M}, \mathrm{L}$, or $\mathrm{I} ; \mathrm{X}=\mathrm{P}, \mathrm{Q}, \mathrm{L}, \mathrm{G}$, or $\mathrm{D} ; \neq \mathrm{X}=\mathrm{G}, \mathrm{Q}, \mathrm{I}, \mathrm{Y}$, or $\mathrm{D}$; Sthis sequence was found in several individual IEF $\mathrm{pH}$ fractions, rather than among those in the whole CSF (data not shown).

the appendix). Four of 14 patients with multiple sclerosis and no control patients $(\mathrm{p}=0.049$, Fisher's exact probability) shared the motif PWX $\mathrm{WLX}_{2}$, where $\mathrm{X}_{1}=\mathrm{P}, \mathrm{Q}, \mathrm{L}, \mathrm{G}$, or $\mathrm{D}$, and $\mathrm{X}_{2}=$ G,Q,I,Y, or D. The probability for the occurrence of any 4/6 amino acid match in the same positions for four patients with multiple sclerosis is at most $\approx 7.0 \times 10^{-5}$, (as shown in the appendix). Although cross contamination by selected phage is always a consideration, it is unlikely because uninfected K 91 Kan $E$ coli never yielded colonies in the selective media. In the case of the RRPFFX motif, patients 2 and 4 were repeated several times over a three year period as coded unknowns and yielded very consistent results including the RRPFFX motif (table 1). Multiple sclerosis patients 12 and 13 were also tested as coded unknowns and had different underlying DNA sequences, as well as an amino acid sequence in patient 13 different from any of the others. In the case of the PWX $\mathrm{WLX}_{2}$ motif, each patient had unique amino acid sequences. Several other motifs were selected by two patients with multiple sclerosis alone or with one or two controls (table 1), but given the large number of clones sequenced, such pairs could have occurred by chance.

To interpret the significance of the amino acid motifs selected by these patients and controls, GenBank was searched for proteins containing related sequences. ${ }^{29}$ The RRPFF motif is found in the Epstein-Barr virus EBNA-1 protein, $\alpha \mathrm{B}$ crystallin, and in the $65 \mathrm{kDa}$ nonstructural cytomegalovirus antigen. None of the other sequences selected had any relation to known or putative autoantigens associated with multiple sclerosis such as myelin basic protein, myelin proteolipid protein, or myelin oligodendrocyte glycoprotein. There were no consistent associations with other human proteins or viruses among the patients with multiple sclerosis or controls.

Because of the repeated finding of the RRPFF motif and its occurrence in the Epstein-Barr virus protein EBNA-1, we synthesised the peptide AEGARRPFFHGAAGETVESKbiotin (MS-1) to approximate the RRPFF sequence as it would be presented by the $\mathrm{N}$ terminal 20 amino acids of the pIII protein in the phage library, with the substitution of $E$ for $D$ at position 2 to avoid cyclisation between the $\mathrm{D}$ and the adjacent $G$ in the native sequence during synthesis. Table 4 shows that when tested against normal human serum samples, there is a very clear relation to prior infection with Epstein-Barr virus. Only one of 32 patients without antibodies to Epstein-Barr virus had antibodies to the RRPFF motif, and that patient had a very low titre. Furthermore, 35 of 56 (62.5 $\%)$ patients positive for Epstein-Barr virus antibody had positive titres to the RRPFF motif, and this percentage was similar among EpsteinBarr virus seropositive patients with multiple sclerosis $(n=15)$. We also studied 10 patients with antibody to cytomegalovirus but no antibody to Epstein-Barr virus. Only one had antibody to the RRPFF motif, and as indicated above, the titre found in this patient was minimally above the cut off.

Individual $\mathrm{pH}$ fractions were recovered from preparative isoelectric focusing gels and used to select phage clones. Table 2 shows a representative patient. Generally only one and occasionally two motifs were found in these narrow $\mathrm{pH}$ fractions with motifs often overlapping adjacent fractions. Interestingly the dominant motif in patient 4 (table 2) seems to be present with some degree of variation across the entire $\mathrm{pH}$ gradient, a finding shared in isoelectric focusing fractions from patient 5 for the motif AVYRPP (data not shown). It is unclear why the RRPFF motif was not selected among the individual fractions despite being selected by whole CSF from patient 4 on three separate occasions. The RRPFF antibodies could have been outside the $\mathrm{pH}$ range of the fractions tested or among the clones from fraction 16 which were accidentally lost.

To determine whether the motifs selected from the phage library were the actual target(s) of individual oligoclonal bands, antigen specific immunoblotting was performed. The figure shows the total IgG banding pattern from a representative patient (No 13). The arrows indicate 8 MS-1 specific bands which have their counterparts in the total IgG bands, certainof which appear to be on the edge of an IgG oligoclonal band suggesting more than one component to the IgG band. At least one (or more) specific band(s) has no counterpart among the total IgG bands. The specificity of these findings is supported by the observation that only a subset of the total IgG oligoclonal bands bind specifically to MS-1. We also performed antigen specific isoelectric focusing using a biotinylated 20 mer which

Table 4 Relation of serum antibody to the RRPFF containing peptide (MS-1) and Epstein-Barr virus among multiple sclerosis and control populations

\begin{tabular}{lll}
\hline & \multicolumn{2}{c}{ Antibody to RRPFF peptide* } \\
\cline { 2 - 3 } & Positive & Negative \\
\hline Antibody to EBV viral capsid antigent & \\
Positive & $35(10) \ddagger$ & $21(5)$ \\
Negative & $1 \leqq$ & $31 \S$ \\
\hline
\end{tabular}

$\star$ Positive $=\mathrm{OD} \geqslant 0.2$; $+\mathrm{VCA}$ positive $=\mathrm{IFA}$ titre $\geqslant 1: 10$; $\neq$ numbers in parentheses are patients with multiple sclerosis. All were VCA positive; \includes 10 patients who were EBV VCA negative, but CMV positive, one of whom had a low but positive $(\mathrm{OD}=0.27)$ titre to the RRPFF peptide. 


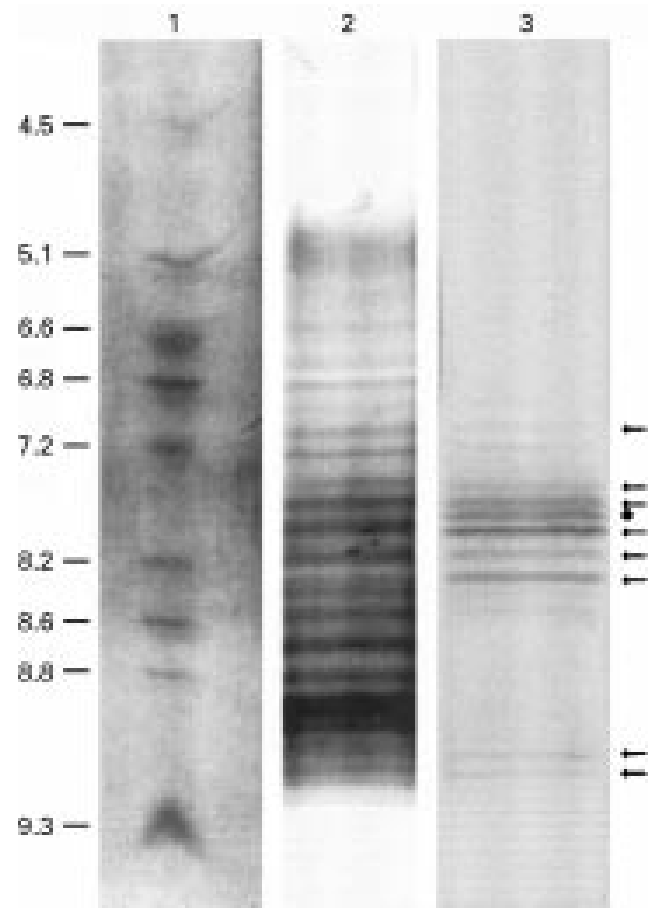

Antigen specific immunoblot with MS-1 compared with total IgG oligoclonal band pattern for multiple sclerosis patient 13. Original gels were scanned with a Nikon Scantouch and digitally aligned with Adobe Photoshop 4.0 and Adobe Pagemaker 6.0 software using a power computing 8500/9100 Power MAC. Arrows show MS-1 antigen specific bands that seem to line up with their counterparts in the total IgG oligoclonal band pattern. Some of the MS-1 antigen specific bands seem to align best with the edge of one of the IgG bands, suggesting that the $M S-1$ specific band is a component of the total IgG band. The MS-1 specific band marked with a bullet (•) does not align with any of the total IgG bands. Lane $1=p I$ markers; lane $2=$ total $I g G$ specific immunoblot; lane $3=M S-1$ specific bands $C S F$.

differs from MS-1 only in positions 5-10 (AEGAIDKPHFGAAGAETVESK-biotin) derived from a motif (shown in bold) selected by a human myeloma protein. No binding of any kind was found by antigen specific immunoblotting with this peptide.

\section{Discussion}

This study shows that phage display libraries can potentially be used to identify the molecular targets of some of the oligoclonal bands in patients with multiple sclerosis. We found that five of 14 patients with multiple sclerosis selected the RRPFF motif from the phage library. When tested with the synthetic peptide, only those with prior Epstein-Barr virus infection had antibodies to this epitope. Serological surveys $^{30-32}$ have shown that essentially $100 \%$ of patients with multiple sclerosis are EpsteinBarr virus seropositive compared with only $89 \%$ of age and sex matched controls. This difference was highly significant because of the large number of patients studied $(\approx 500)$. Furthermore, Bray et $a l^{33}$ showed that CSF from $85 \%$ of patients with multiple sclerosis contained antibodies that reacted specifically with EBNA-1 in western immunoblots compared with only $13 \%$ of Epstein-Barr virus seropositive control patients with other neurological diseases.
Although we remain uncertain as to why some patients with multiple sclerosis selected the RRPFF motif whereas others did not, a possible explanation could be the extremely low probability of selecting any identical sequences out of a library of over $10^{7}$ different hexamers. Secondly, the serum ELISA data (table 4) suggest that not all people with or without multiple sclerosis are capable of making antibody to RRPFF, even if they have been previously infected by Epstein-Barr virus. Cheng $e t a l^{34}$ reported data consistent with this finding using consecutive 20 mer peptides spanning the entire EBNA-1 molecule. Only $28 \%$ of normal subjects had IgG antibodies reactive with the 20 mer which contained the RRPFF motif. ${ }^{34}$

Another important reason for the diversity of sequence motifs is related to the behaviour of the phage display library itself: according to Smith, who developed these methods and shared them and the phage with us for this work, if a monoclonal antibody is known to recognise a linear epitope, in his experience it "always selects a motif from the 6 mer library which closely resembles the eliciting epitope" (G Smith, personal communication, 1994). If the monoclonal antibody is known to recognise a conformational epitope, the chances are about $50 \%$ that a consistent motif (a mimotope) will be selected. Mimotopes are sequences which bear no amino acid sequence resemblance to the epitope to which an antibody is directed, but which by "chance" have a configuration which fits the antibody binding site. As most antibodies are directed at conformational epitopes, most patient oligoclonal bands would be expected to select mimotopes, which would produce the observed consistency within a given patient, but very little consistency between patients.

The nature of the oligoclonal bands themselves adds further complexity. Walsh et $a b^{35}$ studied multiple sclerosis CSF by two dimensional gel electrophoresis. $\mathrm{He}$ found that fractions of $0.1-0.3 \mathrm{pH}$ units in the isoelectric focusing gradient which seemed to contain a single oligoclonal band on isoelectric focusing, could be resolved into several separate L chain spots. On this basis, he concluded that such $\mathrm{pH}$ fractions generally contain one to three dominant monoclonal antibodies, or 50-70 total/ patient with multiple sclerosis. Roström ${ }^{36}$ and Vartdal et $a l^{12}$ also noted that in some patients more than one viral antibody was occasionally associated with the same oligoclonal band. The implication of these studies is that each of the oligoclonal bands contains multiple monoclonal antibodies within what may seem to be a single oligoclonal band by isoelectric focusing. Our studies of preparative isoelectric focusing are consistent with this view in that several $\mathrm{pH}$ fractions of $0.1-0.2 \mathrm{pH}$ units selected more than a single motif.

Occasional MS-1 specific bands could not be aligned with a band in the total IgG oligoclonal band pattern. The finding that CSF contains oligoclonal bands below the limit of detection by conventional IgG staining has been demonstrated in the past by antigen 
specific immunoblotting. ${ }^{11-14}$ Franciotta et $a l^{37}$ have shown that even in HIV infected patients with documented CNS infections due to toxoplasmosis and cytomegalovirus, oligoclonal bands specific for these agents are demonstrable by antigen specific immunoblotting in CSFs lacking oligoclonal bands by IgG staining. Thus the fact that motifs were selected by our controls and one patient with multiple sclerosis without classic oligoclonal bands is probably best explained by the relative lack of sensitivity of total IgG staining compared with antigen specific immunoblotting and by the sensitivity of the selective methodology using the phage library.

Recently, van Noort et $a l^{88}$ identified a small heat shock protein, $\alpha \mathrm{B}$ crystallin, as the component of an extract of myelin from patients with multiple sclerosis, which most strongly and consistently elicited lymphocyte proliferation by lymphocytes from patients with multiple sclerosis compared with myelin from control brain tissue. Interestingly, the linear sequence RRPFF is found in $\alpha \mathrm{B}$ crystallin. Van Noort et $a l^{39}$ has subsequently proposed that stress or other triggers cause the production of $\alpha \mathrm{B}$ crystallin within oligodendroglia and that the $\alpha \mathrm{B}$ crystallin becomes incorporated into myelin breaking the normal immunological tolerance to myelin. It is also conceivable that for some subjects infection with Epstein-Barr virus leads to immune recognition of the RRPFF which breaks the normal immunological tolerance to $\alpha \mathrm{B}$ crystallin. Such a hypothesis could account for the strong epidemiological association of prior Epstein-Barr virus infection in patients with multiple sclerosis. ${ }^{40} 41$

Cortese et $a l^{42}$ have carried out a similar study of CSF from patients with multiple sclerosis using the phage display library approach. They used two different 9 mer libraries expressed on the pVIII protein, one of which was constrained by flanking cysteine disulphide bonds. They screened a large number of epitopes selected by CSF from two patients with multiple sclerosis by serological means to find those recognised by most patients with multiple sclerosis. Three different candidate amino acid motifs were ultimately tested and whereas they were recognised with equal frequency by serum from both multiple sclerosis and control patients $(\approx 50 \%, 5 \%$, and $25 \%$ respectively for the three motifs studied), only four of 55 patients with multiple sclerosis had CSF which reacted with one of these three motifs. None of the three motifs show sequence homology to any of those selected in our study. They did not test their motifs by antigen specific immunoblotting to determine whether they corresponded to specific oligoclonal bands. The differences between their findings and ours most probably arise from the use of a different phage library, which could influence the statistical likelihood of selecting related sequences. In other words the probability of selecting a mimotype could be very different between the two libraries, which could vastly decrease the chances of finding common motifs.

Dybwad $e t a l^{43}$ used three different phage libraries to study CSF from one patient with multiple sclerosis and found amino acid motifs with significant linear homology to human collagen, a $68 \mathrm{kDa}$ neurofilament protein, and several herpesviruses. One of the motifs they found with a hexamer library, PRnpFF, where $\mathrm{n}=$ neutral non-polar residues and $\mathrm{p}=\mathrm{G}$ or $\mathrm{P}$, is strikingly similar to our MS-1 motif.

In conclusion, the phage display technique can be used to obtain amino acid sequence motifs which can be further tested for relevance to multiple sclerosis. Our initial data identified an epitope shared by Epstein-Barr virus and $\alpha$ B crystallin, both of which are postulated to play a part in the pathogenesis of multiple sclerosis, suggesting that this approach can yield biologically meaningful information.

We are extremely grateful to Dr George Smith, University of Missouri, Columbia, MO, USA for generously providing the phage library, a detailed manual for its use, and his many helpful discussions during the course of this work. We also gratefully acknowledge the support of the Protein Synthesis Core Laboraacknowledge the support of the Protein Synthesis Core Laboratory of the Interdisciplinary Center for Biotechnology Research, University of Florida Gainesville Fl, USA and the staff of the Shands Hospital Clinical Chemistry and Diagnostic Virology Laboratories. We also express a special thanks to those patients who willingly underwent lumbar puncture for their generous contribution. This work ws supported by grants from the National Multiple Sclerosis Society, the Diagnostic Referral Laboratory of the Department of Pathology and Laboratory Medicine, University of Florida, Gainesville, Fl, and by the Gainesville Veteran's Affairs Medical Center, Gainesville, Florida, USA.

Appendix: Calculation of random probability for amino acid sequence matching

(1) Calculation of the probability of a 5/6 match between any two selected sequences, and then for $\mathrm{N}=5$ patients

As there are 20 amino acids and six different positions in the phage library, the probability of a given amino acid in any position is $(1 / 20)^{\mathrm{n}}$, where $n=$ the number of positions to be filled, in this case five The probability for a given amino acid sequence in $5 / 6$ positions is $(1 / 20)^{5}$ $x$ the number of permutations that will also result in a $5 / 6$ match, which is given by the formula: $\mathrm{N} ! /(\mathrm{N}-\mathrm{K}) !(\mathrm{K} !)$, where $\mathrm{N}=6$, the total number of positions, and $K=5$, the number of positions to be specified. Multiplied out, $\left(1 / 20^{5}\right)\left(6 ! /(6-5) !(5 !)=6 / 20^{5}\right.$, which is $1.875 \times 10^{-6}$. To calculate the probability that this sequence will have a $5 / 6$ match with at least one other sequence among the remaining 13 patients with multiple sclerosis studied, we multiply this probability by the number of sequences identified in the "first" patient and then by the total number of remaining sequences identified in the remaining 13 patients. Because different patients had different numbers of clones sequenced, the order in which the matches occur affects the probability. Therefore, we calculated the probability based on assuming the sequence we wish to match was found in the patient with the maximum number of chances to find it, namely 20 , as that was the maximum number of clones/patient sequenced. This yields $1.875 \times 10^{-6}(20)$, which is then multiplied by the number of remaining sequenced clones from the other 13 patients which could have matched one of the first 20 in the first patient. This gives $1.875 \times 10^{-6}(20)(169)$, as there were a total of 169 clones sequenced and 20 were from the first patient. Multiplied out, 
this probability is $6.34 \times 10^{-3}$. For a third patient to have a sequence that matched, we multiply the probability of the match in the first two patients by the probability of a $5 / 6$ match in general-that is, $\left(6.34 \times 10^{-3}\right)\left(1.875 \times 10^{-6}\right) \times$ the number of remaining sequences tested in the remaining patients, which depends on how many clones were sequenced in the second patient, the one that matched the first patient. Thus if the match occurred in the patient who had only six clones sequenced, then the remaining clones which could match the first pair would be 163 . But if the match occurred in one of the other patients with 20 clones sequenced, then only 149 would remain. To calculate the maximum probability, we assume that the first match (and all subsequent matches) occurred in the patients with the fewest number of clones sequenced. Any other order of event will yield a lower probability, because there would be fewer remaining sequences which could possibly match the first pair. Thus we have $\left(6.34 \times 10^{-3}\right)\left(1.875 \times 10^{-6}\right)$ (163), where 163 is the number of clones remaining after the first two patients have been specified. This gives $1.94 \times 10^{-6}$. For the fourth patient, we get $\left(1.94 \times 10^{-6}\right)\left(1.875 \times 10^{-6}\right)(155)$, where 155 is the maximum number of remaining sequences assuming the logic above. This yields $5.63 \times 10^{-10}$, which is multiplied by $\left(1.875 \times 10^{-6}\right)(147)$ for the fifth patient, giving a final maximum probability for all five patients of $1.55 \times 10^{-13}$.

\section{(2) Calculation of the probability of a $4 / 6$ match between any two selected sequences and then for $\mathrm{N}=4$ patients}

In this case, we have $\left(1 / 20^{4}\right)(\mathrm{N} ! /(\mathrm{N}-\mathrm{K}) !(\mathrm{K} !)$, which is $15 / 1.6 \times 0^{-5}$ or $9.375 \times 10^{-5}$. Using the same iterative process and assumptions as above, the maximum probability of four patients sharing a $4 / 6$ match is $7.04 \times 10^{-5}$.

1 Link H, Muller R. Immunoglobulins in multiple sclerosis and infections of the nervous system. Arch Neurol 1971;25:326

2 Hershey LA, Trotter JL. The use and abuse of the cerebrospinal fluid IgG profile in the adult: a practical evaluation Ann Neurol 1980;8:426.

3 Kostulas VK, Link H, Lefvert AK. Oligoclonal IgG bands in CSF: principles for demonstration and interpretation based on findings in 1114 neurological patients. Arch Neurol 1987;44:1041.

4 Mehta PD, Patrick BA, Wisniewski H. Isoelectric focusing and immuofixation of CSF and serum in MS. 7 Clin Immunol 1981;6:17.

5 Delmotte P, Gonsette R. Biochemical findings in multiple sclerosis: isoelectric focusing of the CSF gamma globulins in multiple sclerosis (262 cases) and other neurological diseases (272 cases). I Neurol 1977;215:27.

6 Mehta PD. Diagnostic usefulness of cerebrospinal fluid in multiple sclerosis. Crit Rev Clin Lab Sci 1991;28:233-48.

multiple sclerosis. Crit Rev Clin Lab Sci 1991;28:233-48.
7 Norrby E. Viral antibodies in multiple sclerosis. Prog Med Norrby E. Viral antib

8 Grimaldi ME, Roos RP, Manservigi R, et al. An isoelectric focusing study in herpes simplex virus encephalitis. Ann Neurol 1988;24:227-32.

9 Kaiser R, Dorries R, Martin R, et al. Intrathecal synthesis of virus-specific oligoclonal antibodies in patients with enterovirus infection of the central nervous system. $7 \mathrm{Neu}$ rol 1989;236:395-9.

10 Heller J, Holzer G, Schimrigk K. Immunological differentiation between neuroborreliosis and multiple sclerosis. $f$ Neurol 1990;237:465-70.

11 Cruz M, Olsson MD, Ernerudh J, et al. Immunoblot detection of oligoclonal antimyelin basic protein IgG antibodies in cerebrospinal fluid in multiple sclerosis. Neurology 1987; 37:1515-9.

12 Vartdal F, Vandvik B, Norrby E. Viral and bacterial antibody responses in multiple sclerosis. Ann Neurol 1980;8:248-55.

13 Roström B. Antibodies against viruses and structural brain components in oligoclonal Ig G obtained from multiple sclerosis brain. $\mathcal{F}$ Neurol 1982;226:255-63.
14 Souberbielle BE, Swingler RJ, Davidson DLW, et al. Western blotting analysis in patients with MS using human brain vessels as antigen. Acta Neurol Scand 1992;86:397-402.

15 Mehta PD, Patrick BA, Mehta SP, et al. Specificity of oligoclonal IgG bands against myelin proteins in chronic relapsing EAE in guinea pigs. $\mathcal{F}$ Immunol 1987;138:746-51.

16 Houghten RA, Appel JR, Blondelle SE, et al. The use of synthetic peptide combinatorial libraries for the identification of bioactive peptides. Biotechniques 1992;13:412-21.

17 Scott JK, Smith GP. Searching for peptides ligands with an epitope library. Science 1990;249:386-90.

18 Devlin JJ, Panganiban LC, Devlin PE. Random peptide libraries: a source of specific protein binding molecules. Science 1990;249:404-6.

19 Cwirla SE, Peters EA, Barrett RW, et al. Peptides on phage: a vast library of peptides for identifying ligands. Proc Natl Acad Sci USA 1990;87:6378-82.

20 Felici F, Castagnoli L, Musaccio A, et al. Selection of antibody ligands from a large library of oligopeptides expressed on a multivalent exposition vector. $\mathcal{F} \mathrm{Mol} \mathrm{Biol}$ 1991;222:301-310.

21 Greenwood J, Willis AE, and Perham RN. Multiple display of foreign peptides on a filamentous bacteriophage. $7 \mathrm{Mol}$ Biol 1991;220:821-827.

22 Castagnoli L, Musacchio A, Jappelli R, et al. Selection of antibody ligands from a large library of oligopeptides expressed on a multivalent exposition vector. $\mathcal{F} \mathrm{Mol} \mathrm{Biol}$ 1991;222:301-310.

23 Markland W, Roberts BL, Saxena MJ, et al. Design, construction, and function of a multicopy display vector using fusions to the major coat protein of bacteriophage M13. Gene 1991;109:13-9.

24 Koivunen E, Gay DA, Ruoslahti E. Selection of peptides binding to the alpha 5 beta 1 integrin from phage display library. F Biol Chem 1993;268:20205-10.

25 Lenstra JA, Erkens JH, Langeveld JG, et al. Isolation of sequences from a random-sequence expression library that mimic viral epitopes. F Immunol Methods 1992;152:149-57.

26 Yao Z-J, Kao MCC, Loh K-C, et al. A serotype-specific epitope of dengue virus 1 identified by phage displayed random peptide library. FEMS Microbiol Lett 1995;127:93-8.

27 Schumacher GA, Beebe GW, Kibler RF, et al. Problems of experimental trials of therapy in multiple sclerosis: report by the Panel on the Evaluation of Experimental Trials of Therapy in Multiple Sclerosis. Ann N Y Acad Sci 1965;122:552-68.

28 Keir G, Luxton RW, Thompson EJ. Isolectric focusing of cerebrospinal fluid immunoglobulin G: an annotated update. Ann Clin Biochem 1990;27:436-43.

29 Altschul SF, Gish W, Miller W, et al. Basic local alignment search tool. f Mol Biol 1990; 215:403-10.

30 Sumaya CV, Myers LW, et al. Increased prevalence and titer of Epstein-Barr virus infection and antibody synthesis in multiple sclerosis. Ann Neurol 1985;17:371-7.

31 Bray PF, Bloomer LC, Salmon VC, et al. Epstein-Barr virus infection and antibody synthesis in patients with multiple sclerosis. Arch Neurol 1983;40:406-8.

32 Larsen PD, Bloomer LC, Bray PF. Epstein-Barr nuclear antigen and viral capsidantigen antibody titers in multiple sclerosis. Neurology 1985;35:435-8.

33 Bray PF, Luka J, Bray PF, et al. Antibodies against EpsteinBarr nuclear antigen (EBNA) in multiple sclerosis CSF, and two pentapeptide sequence identities between EBNA and myelin basic protein. Neurology 1992;42:1798-804

34 Cheng H-M, Foong Y-T, Sam C-K, et al. Epstein-Barr virus nuclear antigen 1 linear epitopes that are reactive with immunoglobulin A (IgA) or IgG in sera from nasopharyngeal carcinoma patients or from healthy donors. I Clin Microbiol 1991:29:2180-6.

35 Walsh MJ, Tourtellotte WW, Roman J, et al. Immunoglobulin G, A, and M-clonal restriction in multiple sclerosis cerebrospinal fluid and serum analysis by two-dimensional electrophoresis. Clin Immunol Immunopathol 1985;35:31327.

36 Roström B. Specificity of antibodies in oligoclonal bands in patients with multiple sclerosis and cerebrovascular disease. Acta Neurol Scand 1981;86S:1-84.

37 Franciotta D, Zardini E, Bono G, et al. Antigen specific oligoclonal IgG in AIDS-related cytomegalovirus and toxoplasma encephalitis. Acta Neurol Scand 1996; 94:2158.

38 van Noort JM, van Sechel AC, Bajramovic JJ, et al. The small heat-shock protein $\alpha \mathrm{B}$-crystallin as candidate autoantigen in multiple sclerosis. Nature 1995;375:798-801.

39 van Noort JM. Multiple sclerosis: an altered immune response or an altered stress response? F Mol Med 1996;74 285-96.

40 Martyn CN, Cruddas M, Compston DAS. Symptomatic Epstein-Barr virus infection and multiple sclerosis. $\mathcal{f} \mathrm{Neu}$ rol Neurosurg Psychiatry 1993;56:167-8.

41 Operskalski EA, Visscher BR, Malmgren RM, et al. A case-control study of multiple sclerosis. Neurology 1989;39: 825-9.

42 Cortese I, Tafi R, Grimaldi LME, et al. Identification of peptides specific for cerebrospinal fluid antibodies in multiple sclerosis by using phage libraries. Proc Natl Acad Sci 1996;93:11063-7.

43 Dybwad A, Oystein F, Sioud M. Probing for cerebrospinal fluid antibody specificities by a panel of random peptide libraries. Autoimmunity 1997;25:85-9. 